\title{
Successful Acceptance of Adult Liver Allografts by Intra-Bone Marrow-Bone Marrow Transplantation
}

\author{
Satoshi Okazaki, ${ }^{1,4}$ Hiroko Hisha, ${ }^{1-3}$ Tomomi Mizokami, ${ }^{1}$ Takashi Takaki, ${ }^{1}$ Xiaoli Wang, ${ }^{1}$ Changye Song, ${ }^{1}$ \\ Qing Li, ${ }^{1}$ Junko Kato, ${ }^{1}$ Yasuo Kamiyama,${ }^{4}$ and Susumu Ikehara ${ }^{1-3}$
}

Previously, we have shown that liver allografts obtained from the fetus or young mice are accepted when bone marrow cells (BMCs) from adult mice of the same strain are co-grafted. However, for practical clinical use, it is more convenient to obtain both BMCs and liver from the same adult donors. C57BL/6 mice were irradiated with a single high-dose irradiation or two low-dose irradiations and injected with donor BALB/c (8 weeks old) BMCs intravenously (IV-BMT) or directly into the recipient BM cavity (IBM-BMT). Liver tissues taken from the same donor were, on the same day, engrafted under the kidney capsules. Higher survival rates and more complete reconstitution of donor cells were achieved in the IBM-BMT group than in the IV-BMT group, and this was the case in both irradiation protocols. The acceptance of donor liver tissue was seen in all mice in which hematolymphoid cells were replaced by donor-type cells. The liver grafts of the reconstituted mice showed normal morphology and stained positively with anti-albumin antibody and Periodic Acid Schiff (PAs) staining, indicating that the grafted livers were accepted, had grown, and were functioning. These results demonstrate that the acceptance of allogeneic liver can be achieved by cografting donor BMCs via the IBM route.

\section{Introduction}

$\mathrm{O}$ RTHOTOPIC LIVER TRANSPLANTATION is a wellestablished routine treatment for end-stage liver diseases [1]. The success of this procedure is related, in large part, to the availability of potent immunosuppressive agents for preventing and treating acute and chronic rejection $[2,3]$. These agents, however, require continuous administration and induce a considerable risk of renal dysfunction, opportunistic infections, and so on [4-6]. Without the use of such immunosuppression, all allogeneic hepatocytes are rejected within a few days after the transplantation $[7,8]$. Therefore, the development of a new strategy that does not involve the long-term use of immunosuppressants has been eagerly awaited.

Twenty years ago, we showed that liver allografts obtained from young (1-4 weeks old) mice were accepted in recipient mice that had received bone marrow cells (BMCs) from adult (8 weeks old) mice of the same strain by the conventional intravenous (IV) route 2-3 months beforehand [9]. Moreover, we found that hepatosplenomegaly could be prevented in an animal model of Niemann-Pick disease
(C57BL/KsJ spm/spm) when allogeneic adult BMCs and fetal liver transplantations (to replace the defective enzyme) were performed on the same day [10]. In these recipient mice, the newly developed $\mathrm{T}$ cells had acquired tolerance to both recipient- and donor-type cells. Thus, the co-administration of allogeneic BMCs gives great advantages for the acceptance of liver grafts from the same strain. For practical clinical use, however, it is more convenient to obtain both BMCs and liver from the same adult donor and to engraft the BMCs and liver in the patients on the same day. In addition, to prevent the potentially unfavorable side effects caused by the irradiation conditioning, lower radiation doses are necessary for its routine use, particularly in clinical solid organ transplantations.

Recently, there has been an accumulation of clinical data showing the facilitating effects of bone marrow transplantation (BMT) on liver allografts; the liver grafts are accepted in patients that have received allogeneic BMT from the same donor [11-14]. An attempt at allogeneic liver transplantation, followed by BMT from the same donor by the conventional IV route, was made, and mixed donor-recipient

\footnotetext{
${ }^{1} 1$ st Department of Pathology, ${ }^{2}$ Regeneration Research Center for Intractable Diseases, ${ }^{3}$ Department of Transplantation for Regeneration Therapy (sponsored by Otsuka Pharmaceutical Co., Ltd), and ${ }^{4}$ Department of Surgery, Kansai Medical University, Moriguchi City, Osaka, Japan.
} 
hematopoietic chimerism was achieved without severe acute graft-ersus-host disease (GVHD) [15]. Five months later, however, the patient developed progressive pneumonia and died. These results indicate that the co-administration of donor BMCs induces tolerance and leads to the effective acceptance of the allografts, although further research is needed.

Recently, we have found that the injection of donor BMCs directly into the bone marrow cavity-intra-bone marrow (IBM)-BMT-induces the persistent donor-specific tolerance and the rapid reconstitution of the hematolymphoid system of donor origin in a chimerism-resistant combination [normal $\rightarrow$ MRL/lpr], even if the radiation doses are reduced to sublethal levels $(5.5 \times 2$ Gy with a 4 -h interval) [16]. Moreover, we have found that donor stromal cells injected into the BM cavity offer a suitable environment for MHC-matched hematopoietic stem cells (HSCs) in IBMBMT, whereas there is little migration of donor stromal cells or HSCs into the recipient BM cavity when they entered into systemic circulation by intravenous injection (IV-BMT) [16-18]. It is of interest that the mice receiving the IBM-BMT show no histopathological signs of GVHD, even in refractory BMT settings [16,19]. Moreover, we have shown that more rapid and complete acceptance of organ allografts (islets and legs) can be achieved by the IBM-BMT of donor BMCs than IV-BMT $[20,21]$. Very recently, we have also found that heart allografts can be accepted without either acute or chronic rejection for more than 10 months by co-administration of donor BMCs by the IBM route [22].

These findings prompted us to examine whether IBMBMT might have significant advantages over IV-BMT in the allografts of livers obtained from adult mice, even if the recipient mice only receive conditioning with low doses of irradiation. Moreover, to find the optimal conditioning regimen in allografts, we investigated whether fractionated low doses of irradiation induce more complete reconstitution of donor cells and acceptance of liver grafts than a single high dose of irradiation.

\section{Materials and Methods}

\section{Animals}

C57BL/6 (B6, H-2 $\left.{ }^{\mathrm{b}}\right), \mathrm{BALB} / \mathrm{c}\left(\mathrm{H}-2^{\mathrm{d}}\right)$, and $\mathrm{C} 3 \mathrm{H}\left(\mathrm{H}-2^{\mathrm{k}}\right)$ mice were obtained from Shizuoka Experimental Animal Laboratory (Shizuoka, Japan), and maintained in pathogenfree conditions in our animal facility. All of the mice were kept for at least 2 weeks before the initiation of experiments. Experiments using mice were conducted in accordance with protocols approved by the university's committee for animal research.

\section{Irradiation}

Recipient mice (B6, 8 weeks old) were placed in an acrylic container in a continuous airflow between two opposing ${ }^{137} \mathrm{Cs} \gamma$-ray sources (Gamma cell 40; Nordion International, Kanata, Ontario, Canada). The mice received a single dose $(7.5,8.5$, or $9.5 \mathrm{~Gy})$ or fractionated doses of irradiation with a 4-h interval $(4.5 \times 2,5 \times 2,5.5 \times 2$, or $6 \times 2 \mathrm{~Gy})$.

\section{Liver and BMT}

Liver tissue taken from 8-week-old BALB/c mice was cut into about rice grain-size fragments in RPMI-1640 medium (Nikken Bio Medical Laboratory, Kyoto, Japan) and incubated in medium containing $0.01 \%$ collagenase (Type 1; Sigma St. Louis, $\mathrm{MO}$ ) for $30 \mathrm{~min}$ at $37^{\circ} \mathrm{C}$. The liver fragments were then transferred into $2 \%$ fetal bovine serum/ phosphate-buffered saline (FBS/PBS) and kept in the solution until their engraftment (within $1 \mathrm{~h}$ ). The liver fragments were grafted into the left kidney capsule of each mouse (B6) that had received irradiation 1 day before. The kidney capsules were selected as the sites of liver grafts because we had previously shown that these well-vascularized tissues could easily induce the rapid growth of various grafted tissues (liver, bone marrow, thymus and pancreas) [9,10,23-25]. A small incision was made in the kidney capsule and a single liver fragment was inserted into the subcapsular space.

Donor (BALB/c, 8 weeks old) BMCs were collected from the femoral and tibial bones using PBS containing $2 \%$ (FBS). Soon after the liver grafts, the recipient mice were injected with donor BMCs $\left(1 \times 10^{7}\right.$ or $\left.5 \times 10^{6}\right)$ IV or directly into the $\mathrm{BM}$ cavity (IBM injection). The IBM injection was carried out according to the method described previously [16]. In brief, the region from the thigh to the knee joint was flexed to $90^{\circ}$, and the proximal side of the tibia was drawn to the anterior. A 26-gauge needle was inserted into the joint surface of the tibia through the patellar tendon and then inserted into the bone marrow cavity. Using a microsyringe (50 $\mu \mathrm{l}$; Hamilton Co; Reno, NV), the donor BMCs were injected into the BM cavity.

\section{Surface marker analyses}

Peripheral blood was collected from the recipient mice and peripheral blood mononuclear cells (PBMCs) were prepared using Lymphplyte-M (Cedarlane, Ontario Canada). To distinguish between donor- and recipient-derived cells, the cells were stained with fluorescein isothiocyanate (FITC)conjugated anti-H-2 $\mathrm{K}^{\mathrm{b}}$ and phycoerythrin (PE)-conjugated anti-H-2K $\mathrm{K}^{\mathrm{d}}$ monoclonal antibodies (mAbs) (BD Pharmingen, San Diego, CA). In some experiments, BMCs, spleen cells, PBMCs, and thymic cells were collected from the recipient mice and were double stained for lineage markers (FITC- or PE-conjugated mAbs against CD4, CD8, Mac-1, Gr-1 and B220) and anti-H-2 mAbs (BD Pharmingen). The stained cells were analyzed using a FACScan fluorescenceactivated cell sorter (Becton Dickinson \& Co.; Mountain View, CA).

\section{Histological examinations}

The recipient mice were sacrificed at 2, 4, and 8 weeks after the transplantation. The kidneys with engrafted donor liver fragments were removed and fixed with $10 \%$ neutral formalin. The $4 \mu \mathrm{m}$ sections were stained with Hematoxylin \& Eosin (H\&E) or Masson and Gitter reagents to analyze whether the engrafted liver tissues were intact or had changed to fibrous tissues. To examine the functions of the engrafted liver, the sections were reacted with Periodic Acid 
Schiff (PAS) reagents to detect glycogens. Moreover, the sections were analyzed for the production of albumin. Briefly, the sections were deparaffinized with xylene and methanol and incubated with $0.3 \%$ hydrogen peroxide in methanol for 10 min to block the reactivity of endogenous peroxidase. They were washed in PBS and incubated with $1 \%$ gelatin for $30 \mathrm{~min}$ and then incubated with goat antimouse albumin $\mathrm{Ab}$ (dilution of 1:5,000; Bethyl Laboratories Inc. Montgomery, TX) for $1 \mathrm{~h}$. After being washed with PBS, they were incubated with biotinylated anti-goat immunoglobulin G (IgG) $\mathrm{Ab}$ (Vector Laboratories, CA) at room temperature for 30 min. They were incubated with peroxidase-labeled streptavidin and detected using metal-enhanced 3,3' -diaminobenzidine (DAB).

\section{Electron microscopic examinations}

The kidneys with engrafted liver fragments were fixed with buffered PBS containing 2.5\% glutaraldehyde, $\mathrm{pH} 7.4$, at $4^{\circ} \mathrm{C}$ for $2 \mathrm{~h}$. After being rinsed with PBS, the tissues were postfixed with $2 \%$ osmium tetroxide at $4^{\circ} \mathrm{C}$ for $2 \mathrm{~h}$. Thereafter, the samples were routinely processed, dehydrated with ethanol, and embedded in epoxy resin. Semithin sections $(0.5 \mu \mathrm{m})$ of the kidneys were stained with Toluidine Blue. Ultrathin sections of the selected area were cut on a copper grid, stained with uranyl acetate and lead citrate, and observed using a Hitachi H-7000 electron microscope (Hitachi, Ibaragi, Japan).

\section{Mixed lymphocyte reaction}

Spleen cells from the chimeric mice were observed to assess whether the mice had acquired tolerance to donor cells but still had the ability to react with allogeneic spleen cells. The spleen cells (responder) obtained from the chimeric mice, untreated (age-matched to the chimeric mice) B6 or BALB/c mice were incubated with 15 Gy-irradiated spleen cells (stimulator) from untreated B6, BALB/c and $\mathrm{C} 3 \mathrm{H}$ mice (8 weeks old) for 3 days in 96-well flat-bottomed culture plates (responder, $3 \times 10^{5}$ /well; stimulator, $4 \times 10^{5} /$ well) (6 wells/sample). The culture medium (RPMI-1640) was supplemented with $10 \%$ FBS and $50 \mu \mathrm{M}$ 2-mercaptoethanol. As a control, wells containing only responder cells were prepared. The incubated cells were pulsed with $\left[{ }^{3} \mathrm{H}\right]$ thymidine (TdR) for the last $18 \mathrm{~h}$ of the culture period.

\section{Intracellular cytokine staining}

Three weeks after the transplantation, spleen cells were collected from the chimeric mice and incubated with a leukocyte activation cocktail (intracellular cytokine staining starter kit mouse, 559311, BD Pharmingen). After $4 \mathrm{~h}$ of incubation, the cells were stained by an anti-CD4 mAb, permeabilized, and further stained with $\mathrm{mAbs}$ against interleukin-2 (IL-2), IL-4, or IL-10. The double-stained cells were analyzed using a FACScan, and the percentages of the cells having intracellular cytokines were measured.

\section{Statistical analyses}

Log-rank test and the Student two-tailed $t$-test were used to determine the statistical significances in survival rates and in other experiments, respectively. A $p$ value of less than 0.05 was considered statistically significant.

\section{Results}

\section{Survival and reconstitution in mice that received liver allografts plus IBM-BMT or IV-BMT}

Previously, we have shown that allogeneic BMT, followed by liver allografts from the same mouse strain (2-3 months after BMT), results in the acceptance of the liver allografts [9]. In addition, using an animal model for Niemann-Pick disease, we have shown that the combination of allogeneic BMT $(\mathrm{IV}-\mathrm{BMT})+$ fetal liver allografts leads to the acceptance of the liver tissue, resulting in the recruitment of sphingomyelinase to the recipients [10].

On the basis of these findings, we examined in the present study whether IBM-BMT has advantages over IV-BMT for the acceptance of adult (not fetal) liver allografts, even if the liver grafts were carried out on the same day that donor whole BMCs were injected into the recipients. Whole BMCs $\left(1 \times 10^{7}\right)$ obtained from adult BALB/c mice were injected via the IV- or IBM-route into recipient $\mathrm{B} 6$ mice that had received 7.5, 8.5, or 9.5 Gy of irradiation, and liver fragments obtained from the adult BALB/C mice were then engrafted under the renal capsules of the recipient B6 mice on the same day. At all irradiation doses, higher survival rates were observed in the chimeric mice that had received BMCs from the IBMroute than from the IV route (not significant) (Fig. 1A). To investigate the levels of chimerism, PBMCs were collected from the chimeric mice 8 weeks after the transplantation and were double-stained with anti-H-2 $\mathrm{K}^{\mathrm{b}}$ (recipient type) and $\mathrm{H}-2 \mathrm{~K}^{\mathrm{d}} \mathrm{mAbs}$ (donor type). This time point (8 weeks) was selected because the relative percentage of donor- and recipient-type cells in each chimeric mouse remained at a similar level thereafter (even 8-12 months after the transplantation). The chimeric mice with more than $90 \%$ of donor-type cells in their PBMCs were considered to be reconstituted mice. The percentages of the reconstituted mice were calculated using the surviving mice 8 weeks after the transplantation. In the chimeric mice that had received 8.5 Gy of irradiation (Fig. 1B), significantly higher engraftment of donortype cells was observed in the IBM-BMT group than in the IV-BMT group. In the 9.5 Gy-irradiated group (Fig. 1B), there was a tendency for the engraftment in the IBM-BMT group to be higher than in the IV-BMT group, but the difference was not significant. When the recipient mice were irradiated at a dose of $7.5 \mathrm{~Gy}, 100 \%$ survival was achieved in the IBM-BMT group and $92 \%$ in the IV-BMT group (Fig. 1A). No reconstitution of donor-type cells, however, was observed in PBMCs obtained from the chimeric mice in the IBM- or the IV-BMT groups (Fig. 1B), indicating that such a low dose of irradiation resulted in less side effects in the recipient mice but could not completely remove the recipient's immunocompetent cells and HSCs. The chimeric mice that received higher doses of irradiation showed lower survival rates. This suggests that the higher-dose single irradiation caused acute side effects in the mice and that overall condition of the mice became worse than in the mice that received lower doses of single irradiation (Fig. 1A). 

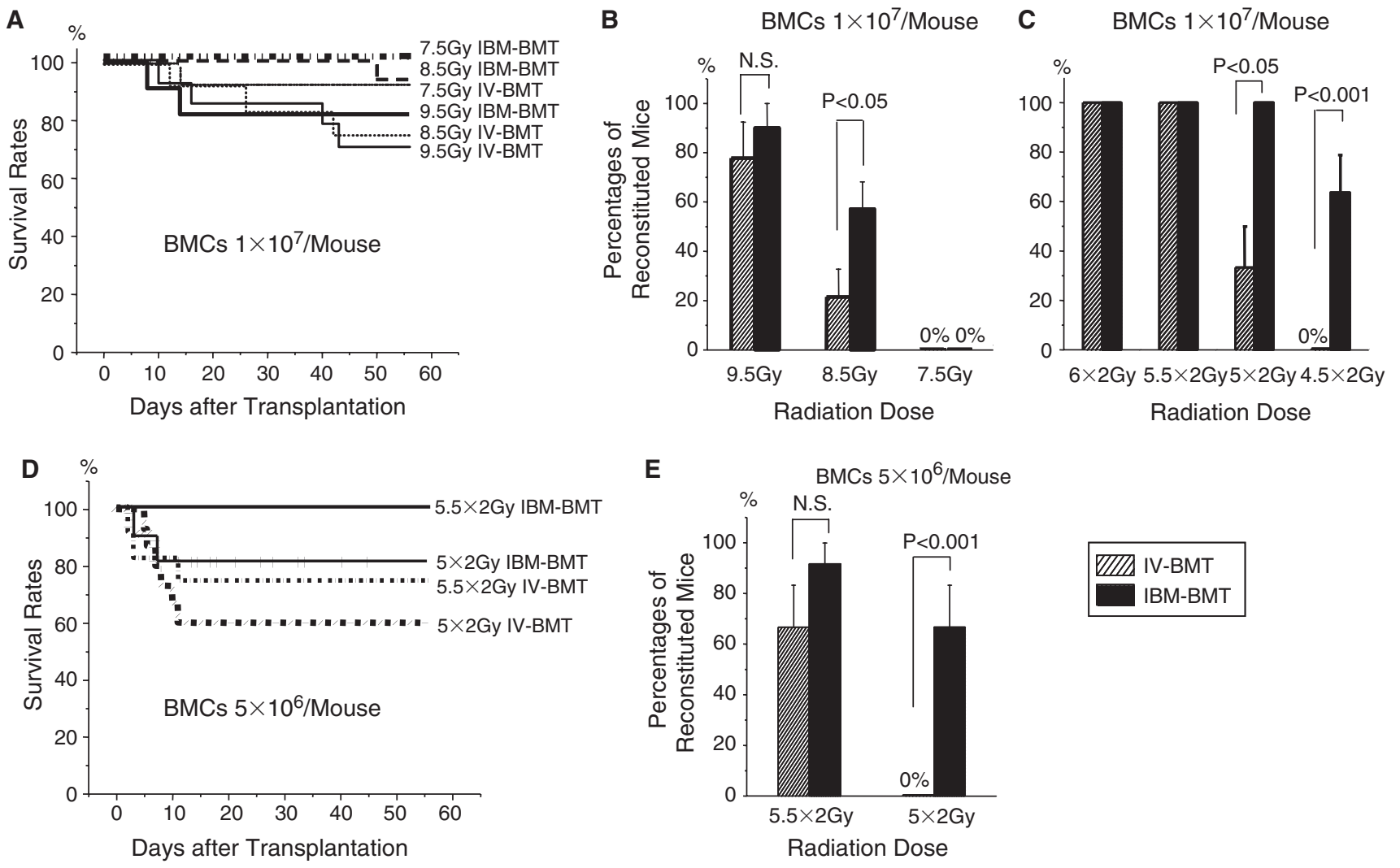

FIG. 1. Survival and reconstitution of chimeric mice. (A) Survival rate in chimeric mice that were exposed to a single dose of irradiation and then received liver allograft and intravenous bone marrow transplantation (IV-BMT) or intra-bone marrow (IBM)-BMT. B6 mice were irradiated with a single dose of 7.5, 8.5, or 9.5 Gy. BALB/c bone marrow cells (BMCs) $\left(1 \times 10^{7}\right)$ were transplanted into the irradiated B6 mice via the IV or IBM pathway 1 day later, and BALB/c liver fragments were grafted under the kidney capsules of the recipient mice on the same day. The survival rate up to 60 days post-transplantation is shown here, because no death due to graft failure was observed thereafter. A summary of three independent experiments (18 chimeric mice per group) is shown. There was no significant difference between the IBM-BMT and IV-BMT groups at each irradiation dose. (B) Percentages of reconstituted mice among chimeric mice that were exposed to a single dose of irradiation and then received liver allograft and IV-BMT or IBM-BMT. BALB/C BMCs $\left(1 \times 10^{7}\right)$ were transplanted into the single dose-irradiated B6 mice via the IV or IBM pathway in conjunction with BALB/c liver fragments. Eight weeks later, PBMCs were collected from the chimeric mice and double-stained with anti-H-2 $\mathrm{K}^{\mathrm{b}}$ and $\mathrm{H}-2 \mathrm{~K}^{\mathrm{d}} \mathrm{mAbs}$. The chimeric mice having more than $90 \%$ of donor-type cells in their PBMCs were considered to be reconstituted mice. Mean \pm SD of three independent experiments (11-18 chimeric mice per group). N.S., Not significant. (C) Percentages of reconstituted mice among chimeric mice that were exposed to fractionated irradiation and then received liver allograft IV-BMT or IBM-BMT. B6 mice were irradiated with two doses of $4.5,5,5.5$, or 6 Gy (with a 4 -h interval). BALB/c BMCs $\left(1 \times 10^{7}\right)$ were transplanted into the irradiated B6 mice via IV or IBM pathway in conjunction with BALB/c liver fragments. Eight weeks later, PBMCs were collected from the chimeric mice and double-stained with anti-H-2K $\mathrm{K}^{\mathrm{b}}$ and $\mathrm{H}-2 \mathrm{~K}^{\mathrm{d}} \mathrm{mAbs}$. Mean \pm SD of three independent experiments (18 chimeric mice per group). (D) Survival rate in chimeric mice that were exposed to fractionated irradiation and then received liver allograft + IV-BMT or IBM-BMT. B6 mice were irradiated with two doses of 5 or 5.5 Gy (with a 4-h interval). BALB/c BMCs $\left(5 \times 10^{6}\right)$ were transplanted into the irradiated B6 mice via IV or IBM pathway at the same time as BALB/c liver fragments. A summary of three independent experiments (18 chimeric mice per group). There was no significant difference between the IBM-BMT and IV-BMT groups at each irradiation dose. (E) Percentages of reconstituted mice among chimeric mice that were exposed to fractionated irradiation and then received liver allograft + IV-BMT or IBM-BMT. B6 mice were irradiated with two doses of 5 or 5.5 Gy (with a 4 -h interval). BALB/c BMCs $\left(5 \times 10^{6}\right)$ were transplanted into the irradiated B6 mice via the IV or IBM pathway in conjunction with BALB/c liver fragments. Two months later, PBMCs were collected from the chimeric mice and double-stained with anti-H-2 $\mathrm{K}^{\mathrm{b}}$ and $\mathrm{H}-2 \mathrm{~K}^{\mathrm{d}} \mathrm{mAbs}$. Mean \pm SD of three independent experiments (10-18 chimeric mice per group). N.S., Not significant.

Previously, we have shown in various donor/recipient combinations that fractionated low doses of irradiation with an interval of $4 \mathrm{~h}$ are more effective in promoting the survival and engraftment of donor cells than a single high dose of irradiation [26]. Therefore, the recipient mice were irradiated at doses of $4.5 \times 2$ to $6 \times 2$ Gy with an interval of $4 \mathrm{~h}$, and $1 \times 10^{7}$ of donor BMCs were injected in conjunction with liver allografts into the recipient mice. As expected, all 
of the chimeric mice survived more than 60 days at all doses of fractionated irradiation (data not shown). At the irradiation dose of $4.5 \times 2$ or $5 \times 2$ Gy, significantly higher reconstitution was achieved in the IBM-BMT group than in the IV-BMT group ( $p<0.001$ and $p<0.05$, respectively) (Fig. 1C). When the recipient mice were irradiated at a dose of $5.5 \times 2$ or $6 \times 2 \mathrm{~Gy}$, all the recipient mice were reconstituted with donor cells, and therefore there was no significant difference in the engraftment between the IBM-BMT group and the IV-BMT group.

Next, we examined whether the injection of half the number of donor BMCs $\left(5 \times 10^{6}\right)$ could reconstitute mice that had received the fractionated irradiation. As shown in Fig. 1D, all of the chimeric mice that had received $5.5 \times 2$ Gy of irradiation, IBM-BMT, and liver graft survived more than 60 days, and $92 \%$ of the thustreated mice were reconstituted with donor cells (Fig. 1E). In contrast, only a $76 \%$ survival rate was obtained in the chimeric mice that had received $5.5 \times 2$ Gy of irradiation, IV-BMT, and liver grafts, and the reconstitution rate was also lower than the IBM-BMT group (not significant) (Fig. 1 D,E). Poor survival rates were observed in the mice that received the lower dose of irradiation $(5 \times 2 \mathrm{~Gy})$ than in the mice that received the higher dose of irradiation (5.5 $\times 2$ Gy). This discrepancy can be explained as follows: immunocompetent cells of the recipient mice remaining after the insufficient irradiation $(5 \times 2 \mathrm{~Gy})$ attacked the donor cells, resulting in a failure to reconstitute the hematolymphoid system and the death of the mice. Although a small number of HSCs likely remained in the recipient mice after insufficient irradiation, they may have no capacity to effect reconstitution. In the mice that received $5.5 \times 2 \mathrm{~Gy}$, a much smaller number of immunocompetent cells remained and a higher reconstitution of donor cells was achieved, especially in the IBM-BMT group. At a dose of $5 \times 2$ Gy, there was a significant difference in the engraftment of donor-type cells between the IBM-BMT and the IV-BMT groups ( $p<0.001)$.

Collectively, these results indicate that higher survival rates and more complete reconstitution of donor-type cells in PBMCs can be achieved by IBM-BMT than by IV-BMT, and that this is so with both the single high-dose and also the fractionated low-dose irradiation protocols. Particularly, the most distinct difference in the reconstitution of PBMCs was observed between the IBM- and the IV-BMT groups of chimeric mice that had received the $4.5 \times 2$ Gy of irradiation plus the administration of $1 \times 10^{7} \mathrm{BMCs}$ (Fig. 1C); $63 \%$ of reconstitution in the IBM-BMT group versus $0 \%$ in the IV-BMT group. Such a clear difference was also seen in the chimeric mice that had received $5 \times 2$ Gy of irradiation plus the administration of $5 \times 10^{6} \mathrm{BMCs}$ (Fig. 1E). Therefore, to analyze the facilitating effects of IBM-BMT further, the following experiments were performed using the chimeric mice that had received the $4.5 \times 2$ Gy of irradiation plus the administration of $1 \times 10^{7} \mathrm{BMCs}$ (Fig. 1C).

\section{Hematolymphoid reconstitution in various tissues obtained from mice that had received liver allografts plus IBM-BMT or IV-BMT}

Next, we examined whether complete multilineage reconstitution was achieved in the various lymphohematopoietic tissues of the chimeric mice that had received $4.5 \times 2$ Gy of irradiation, IBM-BMT, and liver allograft 10 weeks after the transplantation in comparison with the chimeric mice that had received $4.5 \times 2$ Gy of irradiation, IV-BMT, and liver allograft (Fig. 2). The collected cells were double-stained with a panel of mAbs against mature lymphoid, myeloid or erythroid cells and anti-H-2 $\mathrm{K}^{\mathrm{d}}$ mAbs (donor-type). Figure 2 shows representative data of fluorescence-activated cell sorting (FACS) analyses. The phenotypic profiles of cells in the IBM-BMT group showed the reconstitution of donorderived cells in analyzed tissues, whereas those of cells in the IV-BMT group were similar to those of normal B6 mice, and no reconstitution of donor cells was observed.

\section{Histological findings of liver allografts}

Figure 3A shows the time course of histological changes in the liver tissues engrafted under the renal capsules of the recipient mice. As stated above, the mice that had received $4.5 \times 2$ Gy of irradiation, IV-BMT, and liver allograft did not show any sign of the acceptance of donor cells in any of the analyzed tissues (Fig. 2). This was the case with the engrafted liver. Severe tissue damage with hemorrhaging was observed 2 weeks after the grafting, and the infiltration of leukocytes into the engrafted liver was evident at 4 weeks. Finally, the engrafted liver tissue was rejected and replaced by fibrous tissue at 8 weeks. On the other hand, no infiltration of leukocytes was observed in the engrafted liver tissue from the mice that had received $4.5 \times 2$ Gy of irradiation, IBM-BMT, and livergraftat any timeafter the grafting(Fig.3A), and the proliferation of hepatocytes was evident around 8 weeks. Indeed, significant outgrowth exceeding the original rice-grain size was observed after 8 weeks (Fig. 3B). These findings indicate that 8 weeks after the transplantation is an adequate time point for the evaluation of acceptance of the engrafted liver tissue.

It should be noted that the acceptance of donor liver tissue was seen in all of the mice in which hematolymphoid cells were replaced by donor-type cells, whereas all liver allografts were rejected in the mice in which no donor-type hematolymphoid cells were seen. In addition, we observed that liver allografts were rejected in all the recipient mice, which received only $4.5 \times 2$ Gy of irradiation (without BMT) (5 of 5 examined mice), and that all liver allografts to untreated recipient mice (without irradiation and BMT) were rejected ( 5 of 5 examined mice). These results indicate that the reconstitution with donor cells is absolutely necessary for the acceptance of liver grafts.

Masson and Gitter staining was performed to detect fibrous changes in the liver tissues, as shown in Fig. $3 \mathrm{C}$. The rejected liver tissues showed collagen fibers, because the tissues were stained blue in Masson staining and stained silver in Gitter staining. In contrast, such findings were not observed in the accepted liver tissues.

Next, it was important to investigate whether the accepted liver tissues were functioning. Therefore, the production of albumin and glycogen were examined using immunostaining by anti-albumin antibody and PAS staining, respectively (Fig. 3D). In the rejected liver tissues, no cells stained positively in either stainings, whereas every cell showed positive staining in the accepted liver tissues. This observation was confirmed by electron microscopy findings of the accepted liver tissues, glycogenesis being observed in all the cells 

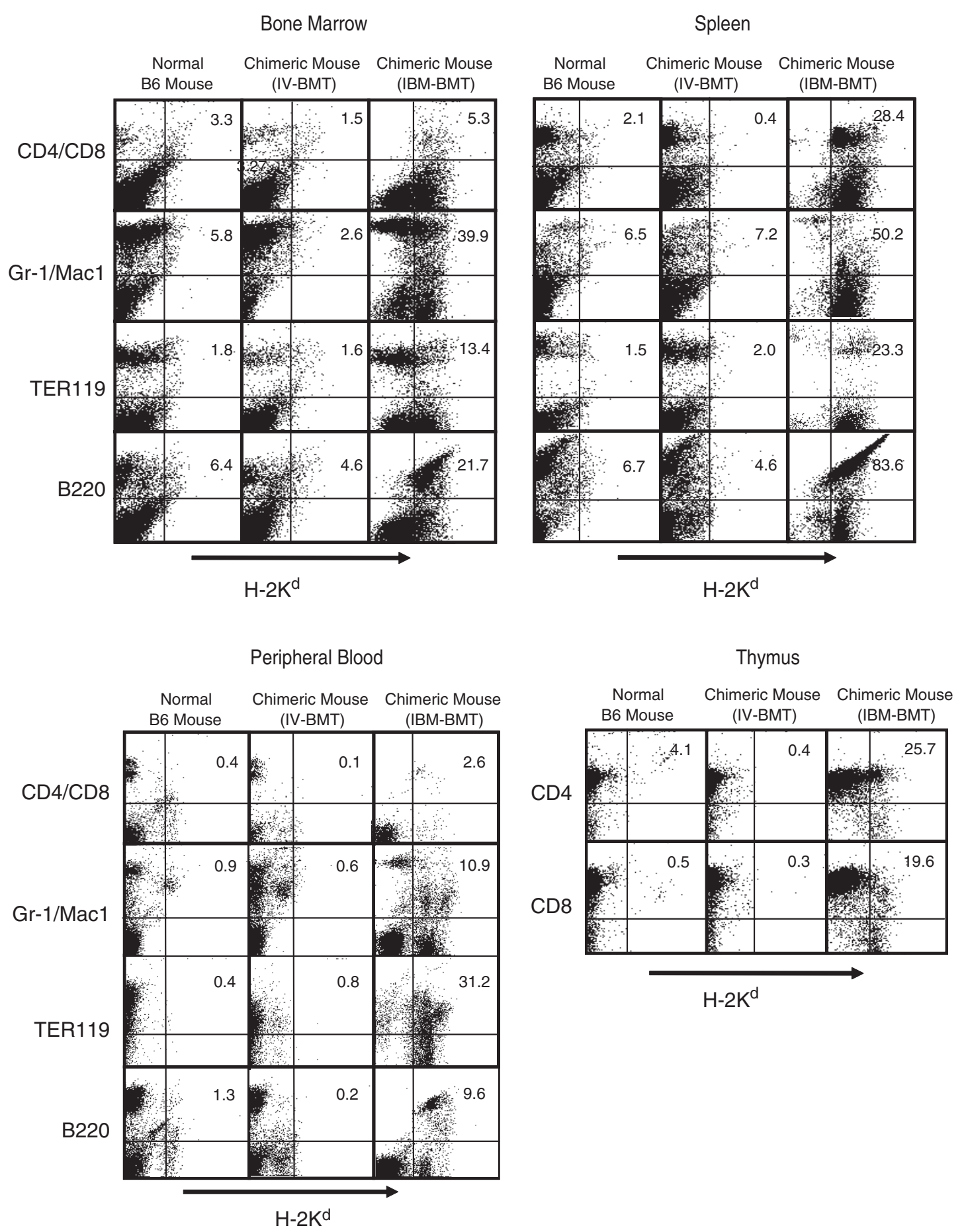

FIG. 2. FACS analyses of lineage-positive cells in bone marrow, spleen, thymus, and peripheral blood obtained from chimeric mice that received $4.5 \times 2$ Gy of irradiation, IV- or IBM-BMT, and liver allograft. (10 weeks after transplantation). Representative staining patterns of three independent experiments.

(Fig. 4B). In addition, the morphology was comparable to normal liver tissue obtained from an untreated 8-week-old BALB/c mouse (Fig. 4A); every cell had a round nucleus, mitochondria, and Golgi apparatus, and micro-bile ducts were also found among the liver cells (Fig. 4B).

\section{Analyses of immunological functions in mice that received liver allografts plus IBM-BMT or IV-BMT}

It was important to investigate whether lymphocytes in the chimeric mice could function normally and had 
A
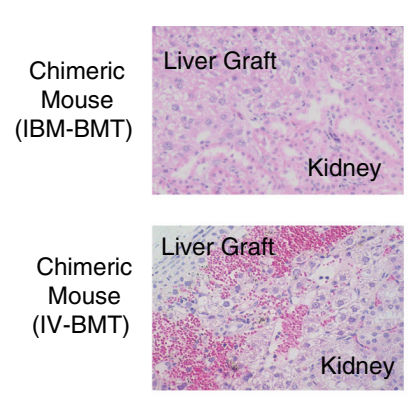

4 Weeks
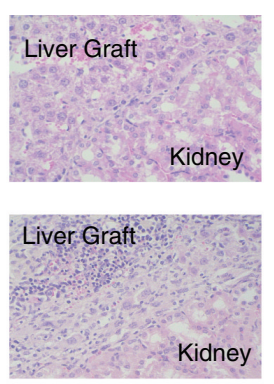

$\underline{8 \text { Weeks }}$
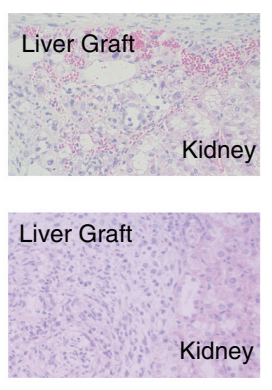

( x200)
B

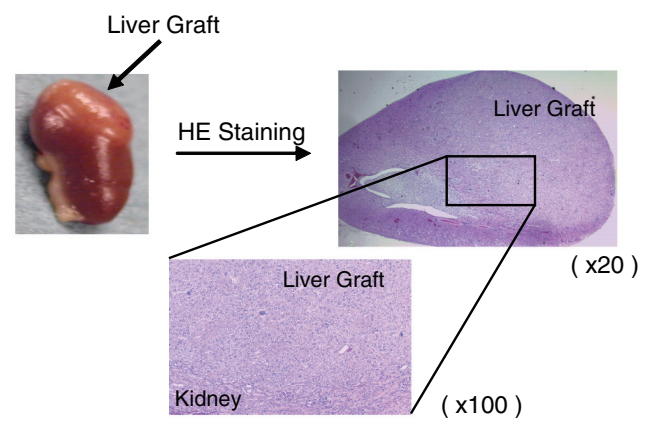

Gitter Staining
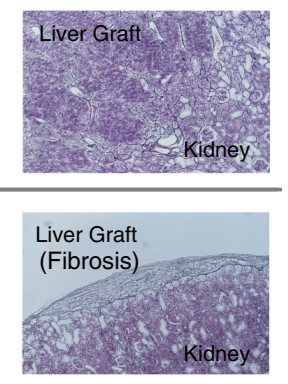

D

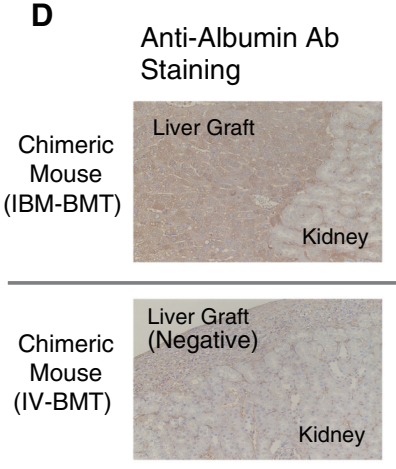

Kidney

\section{PAS Staining}

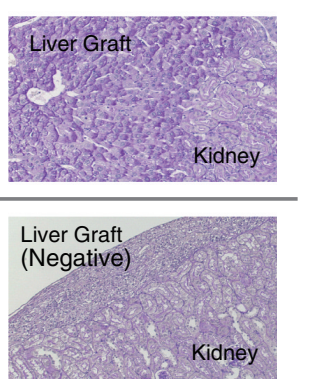

(x200)

FIG. 3. Histological analyses of liver tissues grafted into kidney capsules of chimeric mice that received $4.5 \times 2$ Gyirradiation/intravenous (IV) or intra-bone marrow (IBM) bone marrow transplantation (BMT). (A) Kinetics of histology $(2,4$, and 8 weeks after transplantation) The liver tissues engrafted in the IBM-BMT group showed a normal architecture, and no lymphocyte infiltrations were detected at any time analyzed, showing that the grafts were accepted. However, remarkable lymphocyte infiltrations were observed, particularly at 4 weeks after the transplantation, in the liver tissues engrafted in the IV-BMT group, and the rejected liver tissues were finally replaced by fibrous tissues 8 weeks after the transplantation. Hematoxylin and eosin (H\&E) staining. Representative photographs of six independent experiments. (B) Macroscopic and microscopic observations of engrafted liver fragment (8 weeks after transplantation). The liver tissues engrafted in the IBM-BMT group enlarged in size and cell number. H\&E staining. Representative photographs of more than 10 independent experiments. (C) Fibrous changes in engrafted liver tissues in chimeric mice that received IV-BMT (8 weeks after transplantation). The liver tissues engrafted in the IBM group did not show any signs of fibrosis, whereas fibrous changes were evident in the chimeric mice in the IV-BMT group. Representative photographs of three independent experiments. (D) Production of albumin and glycogen in engrafted liver tissues of chimeric mice that received IBM-BMT (8 weeks after transplantation). Immunostaining using antialbumin antibody and PAS staining showed that the liver tissues engrafted in the IBM group produced albumin and glycogen, respectively. However, no positive staining was observed in the liver tissues engrafted in the IV group. Representative photographs of 10 independent experiments.

acquired tolerance to donor-type cells. To address this question, we employed a mixed lymphocyte reaction (MLR) assay using spleen cells from the chimeric mice that had received $4.5 \times 2$ Gy of irradiation, IV- or IBM-BMT, and liver graft. As shown in Fig. 5, the spleen cells of the mice that received IBM-BMT showed no response to donor $(\mathrm{BALB} / \mathrm{c})$ or recipient (B6) cells, whereas they responded well to the third-party $(\mathrm{C} 3 \mathrm{H})$ cells. This finding indicates that the lymphocytes had acquired immunotolerance to donor cells, but not to third-party cells. In contrast, the spleen cells of the mice that had received IV-BMT showed a response to donor cells.
Finally, to analyze the mechanism by which the IBM-BMT facilitated the acceptance of donor cells, cytokine production from $\mathrm{CD}^{+}$spleen cells obtained from the mice that had received $4.5 \times 2$ Gy of irradiation, IV- or IBM-BMT, and liver graft was investigated 3 weeks after the transplantation. As shown in Fig. 6, the percentages of the cells producing IL-4 and IL-10 [cytokines produced from helper T (Th) 2 cells] were significantly higher in the IBM group than in the IV group. In contrast, the production of IL-2 (a Th1type cytokine) was lower in the IBM group than in the IV group (not significant). Thus, the relative balance of Th1 and Th2 cells skewed into Th2 type in the IBM group, and this 

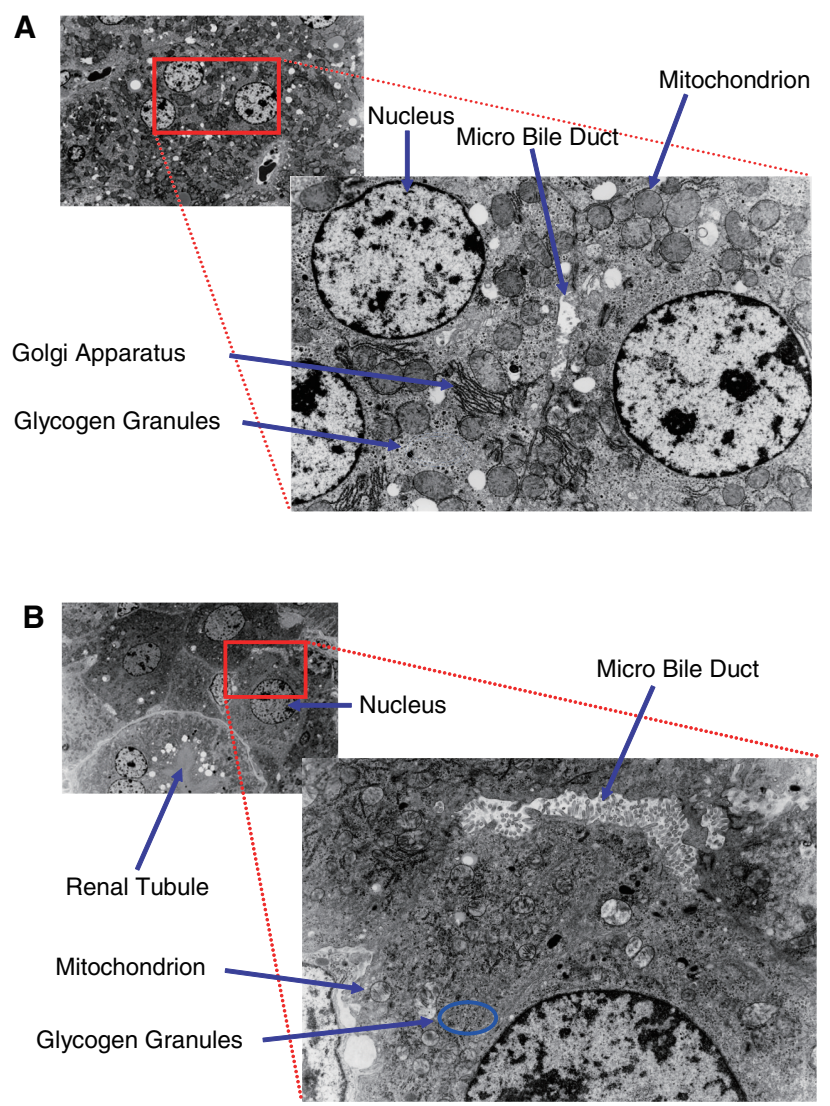

FIG. 4. Ultrastructural analyses of liver tissues. (A) Hepatocytes of normal BALB/c mouse. (B) Liver tissue engrafted into kidney capsules of chimeric mice that received $4.5 \times$ 2 Gy of irradiation and intra-bone marrow-bone marrow transplantation (8 weeks after transplantation). The cells in the grafts showed normal hepatocyte features: large round nuclei, many mitochondria, micro-bile ducts, and glycogen granules. Representative photographs of two independent experiments.

may be one of the reasons why donor-type cells were easily accepted in the IBM-BMT group.

\section{Discussion}

In the present study, using the combination of low-dose irradiation and IBM-BMT, successful liver transplantation was achieved without using any immunosuppressants. It is evident that the engrafted liver tissues were accepted, had grown, and were functioning, because of not only the positive stainings with anti-albumin $\mathrm{Ab}$ and PAS-staining (Fig. 3D) but also the observation of glycogenesis by electron microscopy findings (Fig. 4B). Indeed, hepatocytes in all the liver grafts showed normal morphology; the mitochondria, nuclei, and micro-bile ducts were histologically normal (Fig. 4 B). FACS analyses revealed that the hematolymphoid cells from the mice that accepted the liver allografts had been completely replaced by donor-derived hematolymphoid cells (>90\%) (Fig. 2). Newly developed T cells in the chimeric mice acquired the tolerance to the donor-type cells (but not third-party cells), as shown in the MLR assay (Fig. 5). It is of importance that $\mathrm{T}$ cells from the chimeric mice responded well to foreign antigens, indicating that the immune system and the hematopoietic system in the mice had been completely reconstituted, and that the chimeric mice could prevent the invasion of infectious microorganisms. Moreover, we found that the percentages of IL- 4 and IL-10-producing cells in $\mathrm{CD}^{+}$spleen cells were significantly higher in the IBM-BMT group than the IV-BMT group 3 weeks after transplantation (Fig. 6). However, such differences were not observed longer than 8 weeks after transplantation (data not shown). Therefore, it can be speculated that the polarization to Th2 type in the early phase $(<3$ week after BMT) is very important for the acceptance of donor cells.

Our earlier study [9] has demonstrated that the induction of tolerance to donor-type MHC by allogeneic BMT is the indispensable condition for the acceptance of the donor-type liver tissues from the two experimental results. First, liver allografts alone (without irradiation and allogeneic BMT) resulted in the aggressive rejection of the livers. Second, the chimeric mice that had received $8.5 \mathrm{~Gy}$ of irradiation and allogeneic BMT accepted both BM donortype and recipient-type liver tissues, but not third-party liver tissues. This was the case in the present experiments, because the liver allografts were rejected in all the recipient mice that had not been reconstituted with donor cells. It has been reported that the majority of orthotopic whole liver allografts are spontaneously accepted in untreated recipient mice [27] and rats [28], in contrast to other tissues (kidneys, hearts, and intestines). This phenomenon can be explained by the liver allograft-induced tolerance: the suppression of recipient immune responses by passenger leukocytes and immature dendritic cells contained in the liver allografts $[28,29]$, the neutralization of rejection by a large amount of donor soluble MHC antigen produced by the liver allografts [30], and so on. In the present study, rice grain-size fragments (not whole) of donor livers were transplanted, and the fragments were treated with collagenase before transplantation. Therefore, it is unlikely that the liver allograft-induced tolerance played a key role in the acceptance of liver in the present experimental settings.

Immunosuppressive cytokines are known to be key mediators for alloimmune responsiveness [31], and IL-4 and IL-10 are the most potent immunosuppressive cytokines, because they have a wide immunosuppressive spectrum [32]. Recently, Schmidt-Weber et al. reported that IL-4 enhanced the IL-10 gene expression in vitro [33]. Another in vitro study also showed that IL-10 acts synergistically with IL-4 to inhibit nitric oxide (NO) production from interferon- $\gamma$ (IFN- $\gamma$ )-treated macrophages and suppress their killing activity [34]. In fact, there are many reports showing that IL-4 and/or IL-10 are important cytokines to induce and/ or maintain the acceptance of allogeneic liver grafts in mice [35] and in humans [36].

In accordance with our previous data [26], the two lowdose irradiations (fractionated irradiation) with a 4-h interval were more effective in the survival rates (Fig. 1D), the reconstitution to donor-type cells (Fig. 1C,E), and the acceptance of liver grafts than a single high dose of irradiation (Fig. 1A,B). Such advantages can be explained as follows: (1) the low-dose irradiation reduces the acute side effects on the 


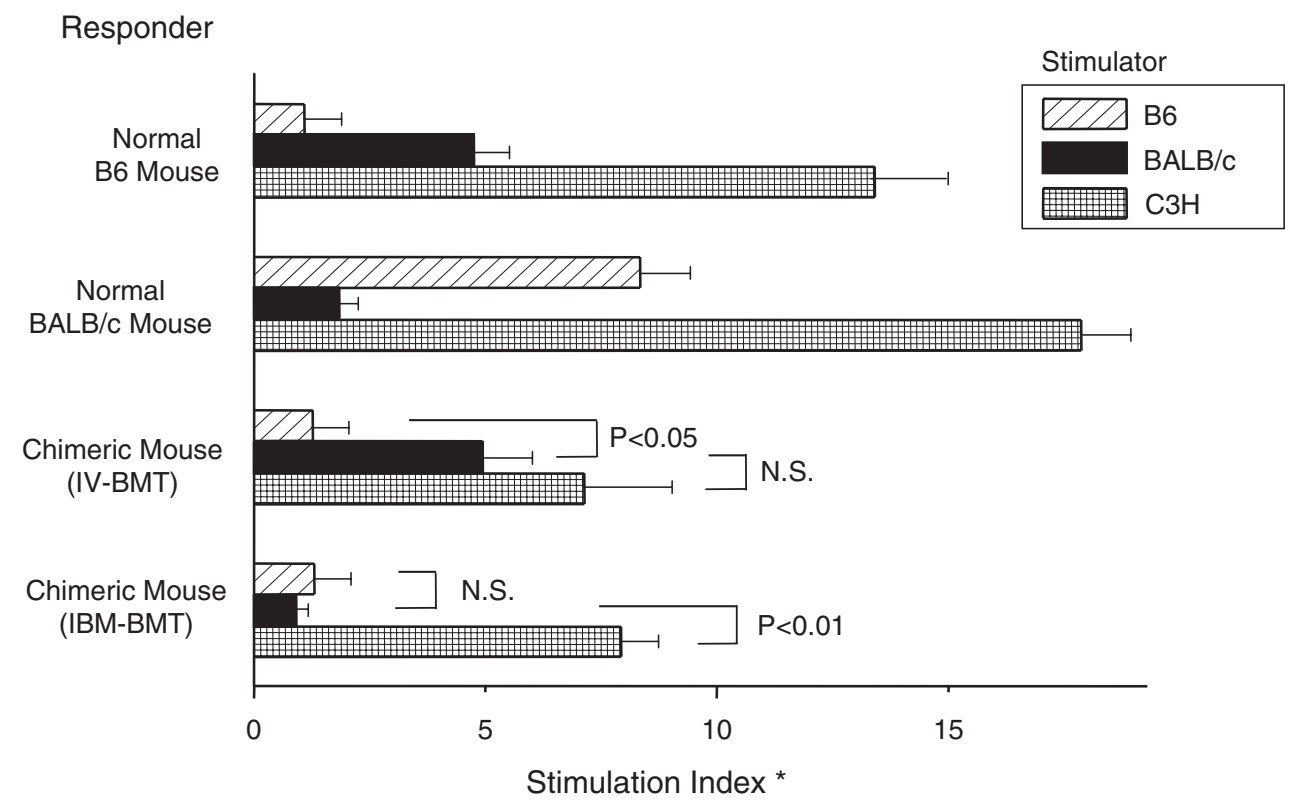

FIG. 5. MLR response of spleen cells obtained from chimeric mice that received $4.5 \times 2$ Gy of irradiation and IV- or IBM-BMT (8 weeks after transplantation). Spleen cells were collected from the chimeric mice 8 weeks after transplantation. Spleen cells were also obtained from untreated B6 or BALB/c mice. The cells were cultured in the absence or presence of stimulator cells. Three days later, $\left[{ }^{3} \mathrm{H}\right] \mathrm{TdR}$ uptake was measured. Tolerance to both donor and recipient types was observed in the chimeric mice in the IBM-BMT group. Mean \pm SD of six wells. Representative data of three independent experiments. $\left.{ }^{*}\right)$ Stimulation index $=\left[{ }^{3} \mathrm{H}\right] \mathrm{TdR}$ uptake on sample well (responder + stimulator) $/\left[{ }^{3} \mathrm{H}\right] \mathrm{TdR}$ uptake on control well (responder alone). N.S., Not significant.

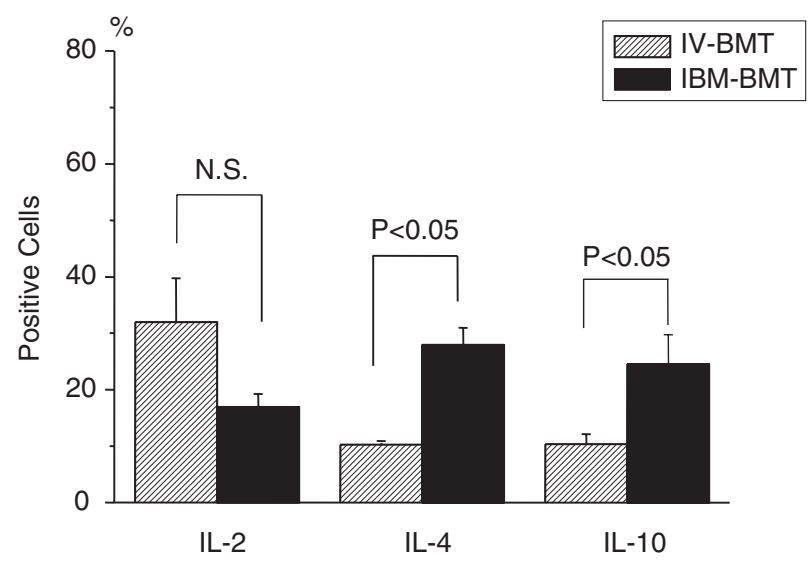

FIG. 6. Intracellular cytokine production in $\mathrm{CD}^{+} \mathrm{T}$ cells obtained from chimeric mice that received $4.5 \times 2$ Gy of irradiation and intravenous (IV) or intra-bone marrow (IBM) bone marrow transplantation (BMT) (3 weeks after transplantation). Spleen cells collected from the chimeric mice were cultured in the presence of a leukocyte activation cocktail for $4 \mathrm{~h}$. Cells treated in this manner were stained with anti-CD4 mAb-FITC. Intracellular cytokines (IL-2, IL-4, or IL-10) were detected by the permeabilization and the following staining with anti-cytokine mAb-PE. The percentages of doublepositive cells (cytokine-producing cells in the $\mathrm{CD}^{+} \mathrm{T}$ cell population) were measured using FACScan. Three chimeric mice per the IV- or IBM-BMT group were analyzed. Data represent the mean \pm SD of three chimeric mice. Representative data of three independent experiments. N.S., Not significant. skin and intestinal mucosa induced by the high-dose irradiation and therefore the general conditions of the recipient mice were greatly improved, (2) the second irradiation effectively removed the recipient HSCs/progenitor cells and the immunocompetent cells that have just re-entered the cell cycle from the dormant stage after the first irradiation. Therefore, if this irradiation protocol was applied to the conditioning before BMT and/or organ transplantation in humans, it might provide significant advantages for the engraftment of donor hematopoietic cells and organs. In the conditioning for patients with end-stage diseases, however, more mild myeloablative regimens [for example, an administration of fludarabine or donor lymphocyte infusion (DLI) combined with two lower doses of irradiation with a 4-h interval than in the present experimental protocol] should be considered.

In summary, the present study demonstrated that successful adult liver allografts could be achieved even in recipients that had been preconditioned with low-dose irradiation when donor BMCs were simultaneously engrafted via the IBM route.

\section{Acknowledgments}

We thank Ms. Y. Tokuyama, K. Hayashi and A. Kitajima for their expert technical assistance. We also thank Mr. Hilary Eastwick-Field, Brian O'Flaherty, and Ms. K. Ando for their help in the preparation of the manuscript. This work was supported by grants from the Haiteku Research Center of the Ministry of Education, the Millennium program 
of the Ministry of Education, Culture, Sports, Science and Technology, the Science Frontier program of the Ministry of Education, Culture, Sports, Science and Technology; grants-in-aid for scientific research (B) 11470062 and scientific research on priority areas (A) 10181225 and (A) 11162221; Health and Labour Sciences research grants (Research on Human Genome, Tissue Engineering Food Biotechnology); and grants from the Department of Transplantation for Regeneration Therapy (Sponsored by Otsuka Pharmaceutical Company, Ltd.), Molecular Medical Science Institute, Otsuka Pharmaceutical Co., Ltd., and Japan Immunoresearch Laboratories Co., Ltd. (JIMRO).

\section{References}

1. Williams JW, SR Vera, TG Peters and S Van Voorst. (1986). Survival following hepatic transplantation in the cyclosporine era. Am Surg 52:291-293.

2. Collins RH. (1994). Tacrolimus (FK506) versus cyclosporin in prevention of liver allograft rejection. Lancet 344:949.

3. The U.S. Multicenter FK506 Liver Study Group. (1994). A comparison of tacrolimus (FK506) and cyclosporine for immunosuppression in liver transplantation. N Engl J Med 331:1110-1115.

4. Wiesner RH. (1998). A long-term comparison of tacrolimus (FK506) versus cyclosporine in liver transplantation: a report of the United States FK506 Study Group. Transplantation 66:493-499.

5. Graham RM. (1994). Cyclosporine: mechanisms of action and toxicity. Cleve Clin J Med 61:308-313.

6. Demetris AJ, JJ Fung, S Todo, J McCauley, A Jain, S Takaya, M Alessiani, K Abu-Elmagd, DH Van Thiel and TE Starzl. (1992). Conversion of liver allograft recipients from cyclosporine to FK506 immunosuppressive therapy- a clinicopathologic study of 96 patients. Transplantation 53:1056-1062.

7. Pratschke J, R Neuhaus, SG Tullius, S Jonas, WO Bechstein and P Neuhaus. (1998). Treatment of cyclosporinerelated adverse effects by conversion to tacrolimus after liver transplantation: long-term results. Transplant Proc 30:1419-1421.

8. Ebata H, I Oikawa and M Mito. (1985). Rejection of allogeneic hepatocytes and fetal hepatic tissue transplanted into the rat spleen. Transplantation 39:221-223.

9. Nakamura T, RA Good, R Yasumizu, S Inoue, MM Oo, Y Hamashima and S Ikehara. (1986). Successful liver allografts in mice by combination with allogeneic bone marrow transplantation. Proc Natl Acad Sci USA 83:4529-4532.

10. Yasumizu R, S Miyawaki, K Sugiura, T Nakamura, Y Ohnishi, RA Good, Y Hamashima and S Ikehara. (1990). Allogeneic bone marrow-plus-liver transplantation in the C57BL/KsJ $\mathrm{spm} / \mathrm{spm}$ mouse, an animal model of Niemann-Pick disease. Transplantation 49:759-764.

11. Rhodes DF, WM Lee, JR Wingard, MD Pavy, GW Santos, BWShaw, RP Wood, MF Sorrell and RS Markin. (1990). Orthotopic liver transplantation for graft-versushost disease following bone marrow transplantation. Gastroenterology 99:536-538.

12. Schlitt HJ, HJ Tischler, B Ringe, G Raddatz, H Maschek, HDietrich, F Kuse, R Pichlmayer R and H Link. (1995). Allogeneic liver transplantation for hepatic veno-occlusive disease after bone marrow transplantation-clinical and immunological considerations. Bone Marrow Transplant 16:473-478.

13. Urban $\mathrm{CH}, \mathrm{A}$ Deutschmann, R Kerbl, H Lackner, W Schwinger, A Konigsrainer and R Margreiter. (2002). Organ tolerance following cadaveric liver transplantation for chronic graftversus-host disease after allogeneic bone marrow transplantation. Bone Marrow Transplant 30:535-537.
14. Andreoni KA, JI Lin and PA Groben. (2004). Liver transplantation 27 years after bone marrow transplantation from the same living donor. N Engl J Med 350:2624-2625.

15. Ringden O, G Soderdahl, J Mattsson, M Uzunel, M Remberger, P Hentschke, H Hagglund, E Sparrelid, A Elmhorn-Rosenborg, F Duraj, H Zetterquist and BG Ericzon. (2000). Transplantation of autologous and allogeneic bone marrow with liver from a cadaveric donor for primary liver cancer. Transplantation 69:2043-2048.

16. Kushida T, M Inaba, H Hisha, N Ichioka, T Esumi, R Ogawa, H Iida and S Ikehara. (2001). Intra-bone marrow injection of allogeneic bone marrow cells: a powerful new strategy for treatment of intractable autoimmune diseases in MRL/lpr mice. Blood 97:3292-3299.

17. Zhang Y, Y Adachi, Y Suzuki, K Minamino, M Iwasaki, H Hisha, C Song, K Kusafuka, K Nakano, Y Koike, J Wang, E Koh, Y Cui, C Li and S Ikehara. (2004). Simultaneous injection of bone marrow cells and stromal cells into bone marrow accelerates hematopoiesis in vivo. Stem Cells 22:1256-1262.

18. Li Q, H Hisha, R Yasumizu, T Fan, G Yang, Q Li, Y Cui, X Wang, C Song, S Okazaki, T Mizokami, W Cui, K Guo, M Li, W Feng, J Katou and S Ikehara. (2007). Analyses of very early hemopoietic regeneration after bone marrow transplantation: comparison of intravenous and intrabone marrow routes. Stem Cells 25:1186-1194.

19. Yahata $\mathrm{T}, \mathrm{K}$ Ando, $\mathrm{T}$ Sato, $\mathrm{H}$ Miyatake, $\mathrm{Y}$ Nakamura, Y Muguruma, S Kato and T Hotta. (2003). A highly sensitive strategy for SCID-repopulating cell assay by direct injection of primitive human hematopoietic cells into NOD/SCID mice bone marrow. Blood 101:2905-2913.

20. Taira M, M Inaba, K Takada, S Baba, J Fukui, Y Ueda, AH Kwon, H Hisha, Y Kamiyama and S Ikehara. (2005). Treatment of streptozotocin-induced diabetes mellitus in rats by transplantation of islet cells from two major histocompatibility complex disparate rats in combination with intra bone marrow injection of allogeneic bone marrow cells. Transplantation 79:680-687.

21. Esumi T, M Inaba, N Ichioka, T Kushida, H Iida and S Ikehara. (2003). Successful allogeneic leg transplantation in rats in conjunction with intra-bone marrow injection of donor bone marrow cells. Transplantation 76:1543-1548.

22. Guo K, M Inaba, M Li, J An, W Cui, C Song, J Wang, Y Cui, Y Sakaguchi, M Tsuda, M Omae, Y Ando, Q Li, X Wang, Feng W and S Ikehara. (2008). Long-term donor-specific tolerance in rat cardiac allografts by intra-bone marrow injection of donor bone marrow cells. Transplantation 85: 93-101.

23. Hisha H, T Nishino, M Kawamura, S Adachi and S Ikahara. (1995). Successful bone marrow transplantation by bone grafts in chimeric-resistant combination. Exp Hematol 23:347-352.

24. Hosaka N, M Nose, M Kyogoku, N Nagata, S Miyashima, RA Good and S Ikehara. (1996). Thymus transplantation, a critical factor for correction of autoimmune diseases in aging MRL/+ mice. Proc Natl Acad Sci USA 93:8558-8562.

25. Iwai H, R Yasumizu, K Sugiura, M Inaba, T Kumazawa, RA Good and S Ikehara. (1987). Successful pancreatic allografts in combination with bone marrow transplantation in mice. Immunology 62:457-462.

26. Cui Y, H Hisha, G Yang, T Fan, T Jin, Q Li, Z Lian and S Ikehara. (2002). Optimal protocol for total body irradiation for allogeneic bone marrow transplantation in mice. Bone Marrow Transplant 30:843-849.

27. Zhang Z, L Zhu, D Quan, B Garcia, N Ozcay, J Duff, C Stiller, A Lazarovits, D Grant and R Zhono. (1996). Pattern of liver, kidney, heart, and intestine allograft rejection in different mouse strain combinations. Transplantation 62:1267-1272.

28. Sun J, GW McCaughan, ND Gallagher, AGR Sheil and GA Bishop. (1995). Deletion of spontaneous rat liver acceptance by donor irradiation. Transplantation 60:233-236. 
29. Wu W, N Zheng, Y Wang, J Fung, L Lu and S Qian. (2006). Immune regulatory activity of liver-derived dendritic cells generated in vivo. Microsurgery 26:17-20.

30. Davies H, S Pollard and R Calne. (1989). Soluble HLA antigens in the circulation of liver graft recipients. Transplantation 47:524-527.

31. Moore KW, A O'Garra, R de Waal Malefyt, P Vieira and TR Mosmann. (1993). Interleukin-10. Annu Rev Immunol 11:165-190.

32. Morita $\mathrm{Y}, \mathrm{M}$ Yamamoto, $\mathrm{M}$ Kawashima, $\mathrm{T}$ Aita, $\mathrm{S}$ Harada, H Okamoto, H Inoue and H Makino. (2001). Differential in vitro effects of IL-4, IL-10 and IL-13 on proinflammatory cytokine production and fibroblast proliferation in rheumatoid synobium. Rheumatol Int 20:49-54.

33. Schmidt-Weber CB, SI Alexander, LE Henault, L James and AH Lichtman. (1999). IL-4 enhances IL-10 gene expression in murine Th2 cells in the absence of TCR engagement. J Immunol 162:238-244.

34. Oswald IP, RT Gazzinelli, A Sher and SL James. (1992). IL-10 synergizes with IL- 4 and transforming growth factor- $\beta$ to inhibit macrophage cytotoxic activity. J Immunol 148:3578-3582.
35. Sefrioui H, J Donahue, EA Gilpin, AS Srivastava and E Carrier. (2003). Tolerance and immunity following in utero transplantation of allogeneic fetal liver cells: the cytokine shift. Cell Transplant 12:75-82.

36. Chung SW, EM Yoshida, MS Cattral, Y Hu and RM Gorczynski. (1998). Donor-specific stimulation of peripheral blood mononuclear cells from recipients of orthotopic liver transplants is associated, in the absence of rejection, with type- 2 cytokine production. Immunol Lett 63:91-96.

Address reprint requests to: Dr. Susumu Ikehara 1st Department of Pathology Kansai Medical University 10-15 Fumizono-cho Moriguchi City, Osaka 570-8506, Japan

E-mail: ikehara@takii.kmu.ac.jp

Received for publication October 10, 2007; accepted after revision November 20, 2007. 
